\title{
¿CAMINOS INTRINCADOS?. LA NARRATIVA DE VARGAS LLOSA Y LAS CIENCIAS SOCIALES
}

\author{
Rommel Plasencia Soto ${ }^{1}$ \\ Universidad Nacional Mayor de San Marcos, Lima-Perú
}

Resumen.- Artículo que hace una introducción a cuatro textos de Mario Vargas Llosa desde las ciencias sociales y la inevitable comparación con la literatura post-indigenista de José María Arguedas. Así mismo se enfatiza que la producción literaria de estos dos novelistas vistos como antípodas de la narrativa moderna peruana, en realidad están conjugadas como dos actitudes rebeldes ante la modernidad, en el que uno remarca la agresión cultural a la libertad del individuo y el otro, el temor a la disolución de nuestras formas culturales.

Palabras claves.- Mario Vargas Llosa; crítica antropológica; ndigenismo; Arguedas

\begin{abstract}
Article that makes an introduction to four texts by Mario Vargas Llosa from the social sciencies and the inevitable comparison with the literature post-indigenist of José María Arguedas, Linkwise is emphatized that the literally production of these two novelist seen like antipodal of the modern peruvian narrative, actually brought together as two rebellions attitudes before the modernity in that one to mark the aggression to the individual freedom and of other one, the dear of the dissolution of our cultural forms.
\end{abstract}

Key Words.- Mario Vargas Llosa; anthropologic critique; indigenismo; Arguedas

"Las sociedades cambian y los caminos se bifurcan" en estos tiempos en que la cultura parece haberse convertido en una verdadera "segunda naturaleza" (Jameson 1998) y que con frecuencia es considerada como la clave principal para querer discernir realidades caracterizadas por el exceso de movimiento, de tiempos y de lugares. Solo así podemos entender por ejemplo, porque hoy la política es analizada de acuerdo a "pautas culturales" y la cultura sea revisada antes que por su propia naturaleza, por sus tramas políticas.

Por eso creemos que son estas las épocas propicias para re-plantearse en cierto modo la relación "problemática" entre la narrativa vargallosiana y su crítica desde las ciencias sociales. Un aspecto importante de esta aparente disociación ha sido la comparación forzada vis a vis con José María Arguedas.

Se suponía que mientras uno expresaba un discurso "criollo" incapaz de percibir la diversidad cultural o mejor, la identidad "nacional" entendida esta como andina, el otro era convertido en paladín de esa misma cultura. La crítica textual también había aparentemente contrapuesto el cosmopolitismo y las sofisticadas técnicas literarias y de composición de Vargas Llosa (sobre todo

\footnotetext{
${ }^{1}$ Departamento de Antropología, Universidad Nacional Mayor de San Marcos, Lima-Perú.
} 
en La casa verde) con el localismo temático y la narrativa cristalina de Arguedas.

Sin embargo, la realidad no es tan sencilla como la exponemos y bien sabemos que las tipologías dicotómicas si bien son útiles para la didáctica y la exposición con propósitos escolares, la realidad social las supera, las confunde y a menudo las sintetiza.

Es en ese sentido que propongo examinar desde las ciencias sociales algunas obras del orbe narrativo de Mario Vargas Llosa que pueden ser más susceptibles para este tipo de análisis.

\section{La mímesis histórica}

Conversación en la Catedral (1969) podría decirse, es una notable saga sobre la corrupción y la mediocridad. La historia personal del protagonista Santiago Zavala es también la historia pública de la dictadura de Odría con la cual esta engarzada.

La confrontación entre estos dos niveles, la del sujeto y la historia, también es tratada por Rushdie en Hijos de la medianoche (1980) en que la vida de Saleem esta íntimamente ligada a la historia de su país. No sólo nace el mismo día en que se proclama la India independiente, sino que los momentos y las tramas más significativas de su vaivén personal están acompasados por los ecos más dramáticos de la nación.

En Conversación en la catedral los personajes tienen además un proyecto a realizar pero que al final se tornan truncos. La imposibilidad de ejercer sus deseos como el caso de Zavalita en quien el periodismo descrito como un medio de vida, le impide ejercer la literatura. Las dos fuerzas en conflicto (el padre y el hijo) no sólo expresan la ruptura violenta con la autoridad paterna (tema sincopado en Vargas Llosa) sino también el drama de no poder ser portadores de esperanzas en una sociedad envilecida en que los premios son recibidos por los inescrupulosos. Por ejemplo Cayo Mierda quien sería la encarnación novelada del Director de Gobierno Esparza Zañartu, se erige a través del chantaje político, el soborno, el crimen y la prostitución.

Los personajes subalternos no pueden sustraerse de su condición socioeconómica, sus aspiraciones se reducen simplemente a un ascenso gradual dentro de su condición de sirvientes o dependientes (Ambrosio, Amalia, la Musa). La frustración y el desaliento se presentan finalmente como las coordenadas en las que se inserta el país:

"un gran canchón rodeado de un muro ruin de adobes color caca, el color de Lima, piensa, el color del Perú"

Los personajes en las siete horas del tiempo narrado, que representan quince años de historia y que en cuatro de conversación con Ambrosio, no se 
convierten en ningún momento en épicos ni transformadores, sino en fracasados, sus mensajes son la derrota. ${ }^{2}$

Con El Hablador (1987) el autor expone el tema de los narradores. Aunque esta perspectiva siempre ha estado presente en sus novelas iniciales: Alberto Fernández y el "Boa" -aunque apegado a un mundo interior- de La Ciudad y los Perros (1963), el periodista miope de La guerra del fin del mundo (1981) e incluso el locutor fantasioso Pedro Camacho de La tía julia y el escribidor (1977), están empeñados en contar historias que muchas veces sobrepasan sus voluntades.

Pero en El hablador, el tema de la doble narración se ejecuta con destreza y agilidad, a tal punto que pareciese una obra menor. Sin embargo, es la más "antropológica" de su orbe narrativo, no sólo porque el protagonista -Mascaritaposee una triple marginalidad: tiene un inmenso lunar en el rostro que lo hace tímido y poco sociable, es judío de madre peruana y sobre todo, estudia etnología en la Universidad de San Marcos.

Y esto último, merece algo de atención en este artículo. En la novela se describe con gracia la pugna entre Porras y Matos Mar por el "alma" de Saúl Zuratas (Mascarita) en la antigua Casona de la universidad. El Departamento de Historia, reducto del clasicismo y porqué no, de cierto pasadismo hispanista, veía con recelo al nuevo Departamento de Etnología que había ayudado a fundar Luis E. Valcárcel.

La desconfianza no sólo era por la promoción de los mejores estudiantes que muchas veces transitaban por el Patio de Letras, sino también por los objetivos propuestos y los mecenazgos.

También lo era por lo que Porras según el novelista:

"tenía un santo horror por la Etnología y la Antropología, a las que acusaba de reemplazar al hombre por el utensilio como protagonista de la cultura y de estropear la prosa castellana" (31)

En efecto, Valcárcel en sus Memorias (1981) explica que una de la razones del apego de la nueva disciplina hacia las misiones norteamericanas, era para desembarazarse de la influencia hispanista que aún tenía mucho poder en la Universidad de San Marcos.

Por otro lado, es innegable la influencia que ha ejercido la amazonía en la obra de Vargas Llosa. Ya esta tempranamente presente en La casa verde (1966) y que quizás el bosque tropical se transmute también en el paisaje agreste del sertón, en las rugosidades andinas, en el paraíso de las Islas Marquesas, en el

\footnotetext{
${ }^{2}$ Es elocuente la escena donde Zavalita visita la clínica en la que su padre agoniza, allí se encuentra después de algún tiempo con su hermana y su antiguo amigo de andanzas miraflorinas convertido ya en su cuñado y en un flamante arquitecto. El protagonista se siente junto a ellos, más pobre, más cholo. Ese horror al desclasamiento -tan vital en la literatura norteamericana- es muy común en los narradores peruanos de clase media como por ejemplo Ribeyro.
} 
infierno verde del Congo belga y nuevamente en el Putumayo, de su última novela.

Por ejemplo para preparar La casa verde, el autor recorrió la selva del Marañón con su libreta en mano como un moderno etnólogo. Para la redacción de EI hablador, el autor contó con la ayuda del Instituto Lingüístico de Verano que en Yarinacocha poseía una verdadera base de operaciones. Ahí, conoció a los esposos Snell (que el autor los Ilama Schneil) ${ }^{3}$ quienes habían trabajado entre los matsigenga del Alto Urubamba.

"Yarinacocha, a la hora del crepúsculo, cuando la boca roja de sol comienza a hundirse tras las copas de los árboles y la laguna de aguas verdosas llamea bajo el cielo azul añil, en el que titilan las primeras estrellas, es uno de los espectáculos más hermosos que yo haya visto" (79)

La amistad de esa pareja de lingüistas y la obra del misionero dominico Joaquín Barriales fueron el cimiento de la novela. No olvidemos además la cubierta con la que la novela usualmente se presenta en la edición de SeixBarral.

Es un fragmento de "Indio luchando con un mono" del pintor naif Henri Rousseau. Y en este momento es que la curiosidad se asoma, pues el "aduanero" Rousseau nunca salió de su natal Francia y sin embargo su fama como pintor se debe a sus cuadros en donde representa lo exótico. El hecho verosímil de que el pintor solo haya conocido las tierras tropicales por los relatos de los soldados expedicionarios franceses que volvían de México, coincide con la lógica del texto de Vargas Llosa: la invención de una realidad pautada por la alteridad y que se alberga en la oralidad, en el texto y en la imagen.

El terma de la doble narración tiene pues aristas inesperadas. La novela es desarrollada mediante dos narradores y cuya relación con el lector despliega distintas perspectivas. Los capítulos en donde el autor pretende una historia con rasgos biográficos se revela al lector como "real". En el otro, es la exposición de la mitología amazónica -y que son sus más bellas páginas- que ha sido recuperada por el "hablador" un sujeto de origen urbano (Mascarita el etnólogo).

Sin embargo, en la narración "real" es en donde nos enteramos de la opción del etnólogo por recuperar la cultura nativa, y en el segundo nivel narrativo, los mitos nos presentan los códigos fundamentales del tiempo y del espacio arawak.

Finalmente la tesis esbozada es en cierta medida, un adelanto de las proposiciones que desarrollará en La utopia arcaica (1996). Es decir, que la conservación de las culturas indígenas son realizadas por agentes externos a ellas, impulsados por el romanticismo y la añoranza de la comunidad original y

\footnotetext{
${ }^{3}$ Wayne Snell (1972) "El sistema de parentesco entre los machingengas" en Historia y Cultura (6): $277-292$.
} 
solidaria, pues el conjunto nativo esta inexorablemente condenado a su contacto con el mundo "moderno".

Al igual que el autor de Tristes Trópicos, Vargas Llosa es consciente que esta conjunción entre lo nativo y lo moderno es en la mayoría de las veces, injusto y perturbador:

"Unos blancos y mestizos miserables, por lo demás, semianalfabetos y descalzos, que vivían en condiciones casi tan ínfimas como sus víctimas. Los excesos feroces que perpetraban con los aguarunas no los hacían ricos, eran apenas para sobrevivir. La explotación, en ese rincón del mundo, se llevaba a cabo a un nivel poco menos que infrahumano"(74)

Ahí están los niveles discursivos hechos por dos narradores de un mismo mundo ("el occidental y moderno") pero en la que uno de ellos se ha mimetizado con la cultura indígena y que según el novelista, sería la más preciada y anhelada expresión del ejercicio antropológico, parodiando de paso, al oficio.

Konig (2001:452-463) ha llamado "oralidad fingida" a este cuidadoso ejercicio que presenta a Vargas Llosa como un hábil artífice -en cuanto disfraz- de la cosmología indígena, y de presentarla con las condiciones estándar de la "oralidad primaria", es decir, de aquella que se realiza sin ningún conocimiento de la escritura.

El otro aspecto de esta novela es el tema de la alteridad. Pareciese que la alteridad física y social se complementase con la alteridad cultural: "De repente, ser medio judío y medio monstruo me ha hecho más sensible que un hombre tan espantosamente normal como tú a la suerte de los selváticos" dice Saúl Zuratas.

Y ese parece ser uno de los temas más discutidos en nuestro novelista. El hecho de presentar a los indígenas como alejados de la civilización, distantes de la razón y que sus lenguas sean percibidas como un cúmulo de sonidos guturales; como describió a los awajun en La casa verde por ejemplo.

Konig acierta cuando muestra que en La tía Julia y el escribidor, el africano polizonte es descrito como un bárbaro porque no puede comunicarse con sus captores y más aún por el hecho de no poder comunicarse en lenguas europeas, las lenguas de la razón: "a quien no se le puede entender no sable hablar" concluye la lingüista.

\section{Los héroes de Vargas Llosa}

Un tema constante de su narrativa ha sido sin duda el de los héroes, pequeños, mundanos, tan comunes y sencillos como nosotros mismos - héroes al fin y al cabo- pero como los vecinos del diabólico edificio en Rosmery's Baby (1968), sorprenden repentinamente por sus cambios tajantes que los hacen únicos y temibles, así se conduzcan hacia la derrota. 
Todos estos personajes tienen en la transgresión su logro fundamental y una vez cumplidas sus metas retornan a lo mundano o ayudan a formar una utopía. Sus actos subversivos les dan fuerza y sentido mientras luchan y es allí, en medio del fragor de la contienda es que se desarrolla la trama principal del discurso. Algo similar ha anotado Bellini (1992:54) sobre Los ríos profundos: el viaje de Ernesto es una huída permanente del mal hacia el bien. Y aunque ello parezca inútil, el sólo desplazamiento permitirá el aprendizaje y la vida del joven protagonista.

Es pichulita Cuellar peleando como en el mito de Sísifo, contra la pesada carga de la castración. Es Alberto, quien desafía el poder del Jaguar y el teniente Gamboa enfrentándose a las normas y los valores (machismo, patriotismo) de una institución paquidérmica. Es el escribidor Pedro Camacho retando la credulidad de los limeños y creando héroes radiales como los personajes de caballería, irreales pero anclados en la sensibilidad de una ciudad que los necesita ante la mediocridad que la rodea.

Es también Zavalita, quizás el más emblemático. No sólo recrea el pasado recordándolo para encontrar el momento constante de su estado actual, sino que también quiere imponerse sus sueños: la de ser escritor. Este terreno de libertad que concede la creación literaria tendrá que ser para lograrlo, inundado de etapas pasajeras y odiosas por prosaicas: un empleo que no se desea, una casa modesta, una esposa humilde, el desarraigo. Mascarita que como etnólogo no encuentra lugar en su barrio de Breña, ni en las expectativas del padre judío, pero que la descubre en el río Urubamba.

Y allí es donde pone en marcha una empresa formidable: la de trasmitir a lo largo del río, en las aldeas dispersas; las bellas historias de este pueblo risueño y trashumante.

Y es también donde él, el marginado, funda su querencia y su utopia en donde la naturaleza se torna purificadora y terapéutica, donde el espacio es nómada y el otro diverso.

Todos los héroes de Vargas Llosa tienen esa impronta. La andaluza y su lucha por los obreros, Paul Gaugin y su escape a un paraíso para explorar sus inquietudes. Casement y su lucha por las victimas del colonialismo y el racismo, aquí y en el África.

Todos desean subvertir al poder y sus normas establecidas, todos luchan por un valor caro al novelista: la libertad. $Y$ al hacerlo tienen que crear sus propias comunidades y sus pequeñas esferas del poder, que muchas veces replican los que ellos mismos se han empeñado en combatir.

En fin son héroes trágicos (o cómicos) y quizás por eso es que en algunos artículos y declaraciones periodísticas, el novelista ha confesado que una de las obras que más admira es Luz de agosto de Faulkner. Y en efecto, es la historia de un héroe trágico. Un mestizo que subvierte el tabú sureño al convivir con una blanca. Cuando el final de un conjunto de circunstancias es perseguido, el protagonista no sale de un círculo vital y como si huyese hacia 
adentro como en anillos concéntricos, es finalmente atrapado y colgado. No puede (no desea) escapar a su destino que se ha ido cimentando en su familia, su ciudad y su región. El grupo que ejecuta al individuo parece ser la violencia racial objetivada en el sur profundo.

En El hombre invisible de Ralph Ellison en cambio, el negro que huye a las ciudades del norte si posee comunicación con la sociedad blanca, a través del jazz, la religión o el sexo. El yo confuso y desorientado lucha antes, con sus cadenas internas y exige más bien reconocimiento de su ser complejo. En Otro país de James Baldwin, Rufo el joven músico negro que malvive con una blanca sureña, se arroja de un puente. Su suicidio es el fracaso de la convivencia en una gran ciudad, pero en la que su parte negra (Harlem) emerge triste e imponente y exige su lugar.

\section{El fantasma de la libertad}

Con La guerra del fin del mundo (1981) todos estos tropos son perfectamente visibles al lector. No sólo es la primera novela que su autor ambienta fuera del Perú, sino que la ideología del novelista se funde con un hecho histórico de dimensiones nacionales. Pues excepto de Conversación en la catedral, esa intención de totalidad nunca alcanza contornos tan precisos e invasivos sino hasta retratar la guerra de canudos.

Si bien la novela trata de la guerra que declara Antonio El Consejero, un líder religioso que decide enfrentarse al ejercito brasileño y lo que este representa, una sociedad secular y un Estado que desea declararse laico- en la sequedad del nordeste, se narran dos conjuntos sociales: la sociedad formal con sus instituciones y del otro, una inmensa comunidad religiosa que alberga a los desheredados de una región considerada una de las más pobres del Brasil.

En la estructura de la novela coexisten cinco historias independientes en la que el único escenario común es la época y la guerra. Cada una de estas historias representan además, cinco esferas políticas e ideológicas: el religioso, el intelectual, el revolucionario, el republicano-liberal y el monárquico, que poseen también cinco finales distintos. En uno es la inútil victoria del ejército, luego la "liberación" del Barón de Caña Brava de la ataduras sociales, el primer amor del Periodista Miope, el empeño de veracidad de Antonio Vilanova de querer contar la historia de El Consejero, y el realismo mágico que pone un término de antología en la novela:

"Es una viejecita sin pelos, menuda como una niña, que lo mira a través de sus legañas: -¿Quieres saber de Joao Abade? Balbucea su boca sin dientes.

-Quiero -asiente el Coronel Macedo-. ¿Lo viste morir?

La viejecita niega y hace chasquear la lengua, como si chupara algo. - ¿Se escapó entonces?

La viejecita vuelve a negar, cercada por los ojos de las prisioneras.

-Lo subieron al cielo unos arcángeles- dice, chasqueando la lengua-. Yo los vi. 


\section{El tiempo original y arquetípico del eterno retorno}

La comunidad del hermano Antonio es una curiosa galería de personajes anómalos y marginales, pero a diferencia de los monstruos de El obsceno pájaro de la noche (1970) no están ensimismados en una villa artificial, sino empeñados en una grandiosa guerra de liberación.

Los dispositivos que sueldan a esa comunidad religiosa son el fanatismo y la lealtad. Ambos encaminan un fenómeno que si bien es una circulación de sentimientos, ha sido descrita -entre ellas por la antropología- como un poderoso factor de movilización social: el mesianismo. Vittorio Lanternari (1965: 349) ha expresado que "Ios movimientos proféticos tienen un indudable carácter religioso".

En ese sentido, el milenarismo del Consejero anunciando la llegada del anticristo permite a Vargas Llosa indagar sobre el fanatismo religioso incubado entre los hombres y las tierras más pobres, pero también le sirve para criticar de forma general el imperio de las ideologías, incluso de aquellas aparentemente fundadas en la razón (Galileo Gall y el Periodista Miope) y que es también la imposibilidad de traducir literalmente la realidad.

Si en Conversación en la catedral, cada personaje que circula en un determinado conjunto social tiene un discurso fragmentado y que leídas todas ellas imposibilita también la comprensión total de la novela y de la realidad que la representa, en La guerra del fin del mundo, esa posibilidad desaparece por completo no obstante el aligeramiento temático del autor.

Tanto el racionalismo moderno como el idealismo si bien aparecen como caminos distintos poseen en realidad, una equivalencia estructural, pues ambos finalmente son discursos construidos por tramas de poder y visiones equivocadas del mundo donde se "pone todo en tela de juicio: la totalidad de la realidad y las aspiraciones totalizadoras de representarla" (Schlickers 1998: 204).

También puede leérsela, como un áspero rechazo al fanatismo popular y al colectivismo, donde la paridad y la carencia son vistas como virtudes, condenando al individualismo que exhala una sociedad y un tiempo nuevos. Quizás ese profundo escepticismo hacia los movimientos sociales con raíces ideológicas, sea un anticipo de su mirada y de su actuación política en la campaña política de 1990.

La violación de Jurema y Sebastiana permite en la novela que el sexo sea el acto por el cual el comportamiento racional se derrumba. Tanto Galileo Gall el anarquista europeo como el Barón de Caña Brava, sucumben ante mujeres humildes. Aquel momento no solo es de transgresión sexual, sino también lo es de índole social: una mujer casada del sertón y una criada, son las encargadas de desbaratar los dictados de la razón y la ecuanimidad. Y aquí llegamos a un tema cardinal en la narrativa de Vargas Llosa: el sexo. 
Es uno de los novelistas peruanos que más ha colocado este mitema como un espacio de goce y plenitud -con excepción de los casos de Jurema y Sebastiana-.

Quizás sus lecturas tempranas de literatura erótica en la biblioteca del Club Nacional y su larga estadía en Francia donde no sólo la literatura moderna corrió el velo del erotismo como en Flaubert o Bataille, sino también en las propuestas de libertad sexual hechas por los intelectuales y los activistas de los años 60 fueron a mí parecer fundamentales.

El sexo ha tenido una suerte desigual en la literatura peruana. Se la ha abordado con más nitidez cuando se ha tratado del Perú provinciano o el de las "clases populares".

Del portazo final de la madrastra del zambuorejon en EI Daño, al sexo tierno y a la vez violento de Maruja en un hotel barato de No una, sino muchas muertes, ha pasado por los alegres cuadros donde se contempla no sólo el paisaje de las quebradas de Huancavelica y Ayacucho, sino también del erotismo y sensualidad de las mestizas (Blasa, Elodia, Olivia, Rosanca) en Cholerías 2 (1974), libro indebidamente olvidado de Porfirio Meneses.

Si bien en algunos relatos sobre la selva peruana la sexualidad se narra casi obligatoriamente, es con Vargas Llosa que alcanza una plenitud estilística y que traduce también un escenario de libertad para los individuos. Así, el sexo junto a la transgresión, el héroe obcecado y la búsqueda de la utopia son sus coordenadas.

Y en eso se diferencia de Arguedas. En el novelista andahuaylino el sexo es antes que una oportunidad de goce y de sensualidad, un acto de dolor y de culpa. ("el amor que sentí por ellas fue el amor de madre. Por otro lado, siento terror ante ellas")

En La utopia arcaica uno de los aportes más originales para comprender a Arguedas es la del sexo atormentado. Dicha mirada no sólo se nutrió de algunos problemas personales que arrastró desde la infancia, sino quizás también de una mirada católico/andina de la sexualidad.

("El catolicismo infundió no sólo temor al goce sino temor a la naturaleza..Tu, Sybila, para mí eres eso, el misterio hecho y prohibido por el catolicismo, el misterio del goce que sólo debe o puede poseerse después de la muerte")

Esa ambivalencia de goce y culpa fue en cierto modo, la clave que organizó la vida social de los Andes hasta la primera mitad del siglo XX. Tanto los mistis como los criollos monopolizaban a las mujeres. Las "blancas" eran su patrimonio exclusivo pues servía para perpetuar los linajes y la heredad, además del prestigio social. Pero las "blancas" eran sujeto de una devoción puritana, casi desexualizadas.

Las "otras mujeres" (indias y mestizas) eran concubinas, amantes, queridas y luego, esposas de comuneros. 
"La imagen de la cholita moviendo los labios en un fluir de historietas de maravilla, lo acompañó por mucho tiempo. No podía olvidar a quien había puesto los más hermosos colores en su vida de infancia. Aunque-golpes que el tiempo nos depara- supo después que aquella que fuera la alegre y esbelta Pisquelacha era ya la gorda mujer de un zapatero" (Meneses 1974: 34)

Quizás se perpetuó esa costumbre feudal traída por los invasores españoles que hizo por ejemplo que Pizarro "entregara" a sus amantes indias -muchas de ellas nobles cuzqueñas- a sus escuderos, tal como lo haría también el Capitán Garcilaso con la madre del Inca. En tal sentido, la seducción era una afición de los hombres no indígenas en la sierra peruana (la mujer campesina era negada pero a la vez deseada, convirtiéndola en sujeto de goce sexual pero socialmente irrealizable) ${ }^{4}$, pero también era visto como un acto censurable y "sucio".

Vargas Llosa arguye en La utopia arcaica que en Arguedas:

"los malvados son siempre corrompidos sexuales" "Sus héroes son siempre abstemios en materia carnal. Rendón Willka es casto, y aquellos malvados que se vuelven buenos, inmediatamente dejan de hacer el amor. Por ejemplo, don Bruno. Ese ser lujurioso, que ha desflorado a infinidad de muchachas de la región, desde el instante en que se vuelve bueno, se desexualiza". (270)

Es por ello que en las páginas iniciales de La tentación de los imposible (1974) celebra no sólo el genio literario del autor de Los Miserables, sino también su farragosa vida sexual y sentimental que no sólo le dota de una fuerza vital para emprender la obra monumental de tipos y situaciones que situó al romanticismo en su elevada cumbre, sino sobre todo, de una vida personal en donde el gusto y los arrestos de Víctor Hugo están enmarcados en el plano de la libertades. Esa libertad que muy bien ejemplifica la cubierta de la edición en castellano del libro de Vargas Llosa: La libertad guiando al pueblo de Delacroix.

El paraíso en la otra esquina (2003) es la última novela que comentamos. Y es a todas luces un texto en donde una vez más, la ideología implícita del autor da rienda suelta. En ella, esta planteada la cuestión de las utopías sociales y personales, situadas en el siglo XIX, que como sabemos fue la época de las utopías más significativas.

Y está también la cuestión de la libertad y de cómo los corsés sociales contra las que luchamos al remontarlas, moldean nuestra personalidad -el héroe vargallosiano- bien penosas y sumisas de los prejuicios o si por el contrario, vislumbran una arrolladora identidad en que la licencia de la vida íntima se corresponde con el paisaje iluminado que reclaman el genio y la creatividad.

\footnotetext{
4 "Las cholitas son deseables" (80) escribe el huantino Porfirio Meneses. Por otro lado Todorov (2003:357-61) registra la estrecha relación entre exotismo y erotismo cuando se detiene en la literatura del viajero Loti.
} 
En esta novela también existe como en El hablador o La tía Julia y el escribidor, la doble estructura narrativa. La historia de Flora ocupa los capítulos impares y los de su sobrino-nieto los capítulos pares, aunque desde luego existen niveles comunicantes.

Flora Tristán es mostrada como una valiente mujer pionera del socialismo y de la defensa de los obreros de "esos hombres cansados, de caras vencidas, que sólo querían olvidar la vida que llevaban" (46) y que intenta forjar una utopia en que las clases sociales se allanen y la riqueza sea redistribuida. Pero esta utopía en Flora, descansa sobre un conjunto de frustraciones personales. No sólo en una herencia paterna que le es negada en un lejano país de America del sur, sino también en las dificultades que la pobreza confiere e incluso, en su fallida vida sexual que la hace acercarse temerariamente a su compañera Olympia. Vargas Llosa quiere entrever que tanto la subjetividad de la luchadora como sus sueños sociales son fallidos.

Sin embargo, Flora Tristán aparece en sus páginas con todo su empeño, con todas sus fuerzas incansables fijando el drama de su fracaso, pero que mientras esta se traduzca como una lucha diaria, no lo es.

Paul Gauguin en cambio se lleva todas las simpatías, no sólo por ser varón como lo ha sugerido Henighan- ${ }^{5}$ sino porque su utopia afincada en el trópico verde y luminoso es más individual y poco comprometida con "la sociedad" y por lo tanto, más cautiva de la creatividad que sólo otorga el arte. Pues este último es visto cómo la suma de las libertades que sólo irrumpe con el orden burgués.

Y sobre esto último, Vargas Llosa ha ido replanteando sus ideas. Del compromiso sartreano con los males de la época, transitando por el escepticismo, hasta la noción de que la literatura es la verdad añadida o para decirlo con sus propias palabras "una hermosa mentira". Ha sido reacio a otorgar valor no sólo a la literatura que él considera "comprometida" como por ejemplo el "realismo socialista", sino también de la conformidad entre el escritor libre y su compromiso político, convirtiéndolo de hecho en un creador "bifronte" y por lo tanto inauténtico. Estas ideas y actitudes no sólo se han plasmado en la polémica con García Márquez sino también con Gunter Grass.

Y aquí provoca compararlo con Arguedas. Las críticas a la obra del autor de Los ríos profundos no han sido por supuesto uniformes. Una corriente ha querido encontrar cierto "escenario" que se corresponde con la validez sociológica y antropológica.

La sierra fue efectivamente así como la cuenta Arguedas: racismo, exclusión, rebelión, es decir, lo que se llamó el "crisol colonial" (Montoya, Nelson Manrique, Gonzalo Portocarrero, Moore entre otros). Esta tradición se fortalece cuando en la etapa final de su vida da ciertos testimonios (sobre todo en su poesía) y concede entrevistas donde enfatiza su militancia.

\footnotetext{
${ }^{5}$ Henighan 2009.
} 
Aunque Manuel Moreno Jimeno y Lily de Cueto -la viuda de Carlos Cueto Fernandini- han dudado de que esta actitud haya sido espontánea y la atribuyen a las urgencias del momento (las invasiones campesinas de Hugo Blanco y las reformas militares) necesarias para comportarse "correctamente". 6

La otra corriente ha sido la de encontrar en su narrativa el traslape hay veces feliz y hay veces conflictivo entre dos mundos ("el andino y el occidental") y que se expresa en una mudanza de los sentimientos y del lenguaje, como por ejemplo la "quechuización" del castellano (Castro-Klaren, Escobar, Cornejo Polar, Rowe).

En esta propuesta Arguedas aparece como un escritor que "hablaba en prosa sin saberlo" pues a partir de su muerte se ha querido encontrar en su obra reflexiones propias de la "posmodernidad": intertextualidad, experimentos con el lenguaje e interculturalidad (como Lienhard), ${ }^{7}$ acercando su obra a la de autores contemporáneos más conscientes de su rol de crear sobre dos mundos que se superponen y se entremezclan, como pueden serlo Kawabata, Rushdie o Arundhati Roy.

Y por último quienes como Vargas Llosa creen ver cierto desorden estilístico en su obra y de enfatizar sobre todo, los niveles de irrealidad y ficción cuando ha narrado sobre el Ande. Esta última ha sido en cierto modo -como juzgaran los lectores- censurados y derrotados cuando en la crítica literaria se han puesto en pugna el "debe ser" y la actuación política de la comunidad intelectual.

Volviendo a El Paraíso en la otra esquina, decíamos que las simpatías del autor por Gauguin se deben a que su paraíso fue construido sobre su disconformidad individual. En efecto un burgués casado convenientemente, con un empleo prometedor en las finanzas parisinas y que de pronto un día se larga a unas islas remotas del Pacífico sur para hacer lo que verdaderamente deseaba: pintar.

En las Islas Marquesas es que convive con la comunidad original y la etnia fraternal, y en ella no sólo se convierte en el artista sino también donde trasunta su libertad sexual libre de tabúes, incluida con la del propio sexo, muy distante de las convenciones sociales de la Europa de fines del siglo XIX.

Si para las dos primeras décadas del siglo $X X$, el vanguardismo -el surrealismo, dadaísmo, cubismo, futurismo- anunciaba una rebelión de las formas estéticas de la burguesía, contra la guerra y el maquinismo capitalista, Gauguin se rebela desde las formas naturales de una isla que "esta fuera de la historia" no solo por su lejanía de occidente, sino también por su estado de escalón anterior a la "modernidad".

\footnotetext{
${ }^{6}$ Pueden verse sus testimonios en una edición de homenaje al escritor en Runa (6) 1977: 1314.

7 Jameson (224-25) señala los Joyce que se configuran en la crítica postmoderna y con ironía también invoca "un Kafka de Deleuze es sin duda un Kafka postmoderno, un Kafka de la etnicidad y los microgrupos, en gran medida un Kafka del tercer Mundo y de la minoría dialéctica, a tono con la política postmoderna y los "nuevos movimientos sociales".
} 
En El piano (1993) film de Jane Campion y ambientada en la Nueva Zelandia de la era victoriana, la moral puritana es subvertida por la liberalidad sexual de los maoríes. El tercer género tiene un lugar ahí, como lo tiene en muchas sociedades no occidentales. Así al paraíso moderno de las ideas socialistas se contrapone el paraíso natural, siendo este último más reconfortante, llevadero y real -porque esta ya dado- aunque finalmente, al igual que las sociedades del Urubamba en EI hablador o la comunidad de El Consejero, sean fugaces y perdidos.

Meseth (2009) lo dice más claramente: "La utopía adopta finalmente la condición de enfermedad, y las muertes de Flora Tristán y Paul Gauguin simbolizan el fin de la era utópica, que permitirá el tránsito hacia nuevos tiempos" (11)

\section{La incómoda comparación}

El punto de quiebre es obviamente con La utopia arcaica, en ella no sólo hace una crítica a la obra de Arguedas sino también en lo que subtitula como las "ficciones del indigenismo". Si bien su análisis de la narrativa arguediana ya había sido hecho anteriormente (sobre todo su ensayo "José María Arguedas entre sapos y halcones.") es la crítica a las ideas del indigenismo lo que le va a reportar los reproches más severos.

En primer lugar, las críticas al indigenismo como un movimiento cultural sustentado por artistas y abogados mistis ya había sido hecha. Thomas Davies, Kristal, de la Cadena y Favre habían remarcado el sustrato no indígena de un movimiento que defendía a los indígenas.

Se había enfatizado que la acción y el discurso indigenistas eran ante todo una representación que había escamoteado una participación directa (política) del mundo indígena. Si bien reconocían que las tradiciones regionales (sobre todo del Cuzco y Puno) se habían inscrito merced a este movimiento, en corrientes de innovación literaria y artística, reconocían sin embargo, que en ausencia de una modernidad real, se prodigaron a sí mismos, sólo una modernidad simbólica y representacional.

Si bien habían democratizado y descentralizado el ejercicio intelectual y que incluso, algunas corrientes se habían radicalizado con el naciente socialismo, el estatus pequeñoburgués de sus representantes más conspicuos había frustrado una verdadera alternativa revolucionaria.

Pero el enfado con Vargas Llosa se debía ante todo, a que su crítica era hecha desde su condición de escritor y desde su ideario (llamémoslo de ese modo) liberal. Es decir criticaban la ideologización en su examen de Arguedas, pero recurrían a las mismas armas para desafiar intelectualmente al novelista arequipeño. 
La utopia arcaica es un libro que personalmente seduce -no es un halago, es solo un sentimiento y como tal, hay seducciones que matan y otras que salvan y prolongan la vida- por su irreverencia, por su audacia ("un libro turbador" lo ha llamado Mujica 1997: 40) y sobre todo por discutir un tema que se supone coto de caza de las ciencias sociales: la discusión sobre la tradición y la modernidad, el futuro de la sociedad andina y el ejercicio antropológico. Y lo hace con herramientas que los toma del arsenal de la crítica literaria y muy pocas de las ciencias sociales -cuando trata esto se nota el asesoramiento de Juan Ossio-. ${ }^{8}$

El libro sin embargo, tienes algunos aportes fundamentales y que complementan o enfrentan los trabajos más representativos que se han ocupado de la obra de Arguedas y que se puede sintetizar en lo siguiente: el énfasis colectivo de los escenarios arguedianos. En efecto, la apuesta por los conjuntos sociales bien delineados (mestizos, indios, señores, costeños, serranos) nos recuerda la importancia de las comunidades en la narrativa indigenista, y que se opone tenazmente a lo que Angvik (2004: 24) ha llamado el "individualismo radical" de Vargas Llosa.

La "ensoñación" de muchos de sus protagonistas y que generalmente son niños como Ernesto. Muchos de estos pasajes corresponden a rasgos autobiográficos del propio Arguedas. Este trastrocamiento infantil de la realidad, se la ha correspondido con los sistemas cognitivos no occidentales el pensamiento salvaje- como el andino, en que las normas que rigen la sociedad y el orden natural están superpuestas.

El otro asunto es la naturaleza animada, lo que Vargas Llosa y otros críticos han denominado el sentimiento panteísta en Arguedas. En efecto, en el pensamiento mítico amerindio el orden natural es a la vez el orden del universo. Plantas y animales adquieren de pronto cualidades humanas y muchas personas cuando transgreden normas esenciales (como la reciprocidad en el reparto de alimentos y de mujeres) se "zoomorfizan" en animales con los cuales se ha establecido previamente una cierta analogía.

(Rasu- Niti era hijo de un Wamani grande de una montaña con nieve eterna. El, a esa hora, le había enviado ya su "espíritu": un cóndor gris cuya espalda blanca estaba vibrando")

Sin embargo en el área andina después de mas de 400 años de evangelización cristiana muchos de estos principios desaparecieron o se incorporaron a la liturgia y el ritual católicos que como sabemos, absorbió aquí y en otras latitudes, las tradiciones pre-cristianas. Sin embargo el debate aún continúa.

Para muchos historiadores la lógica de los concilios limenses se imbricó hábilmente en el mundo religioso pre-hispánico. Para otros, herederos del

\footnotetext{
${ }^{8}$ Los libros de Ossio que pueden haber influido en Vargas Llosa para algunos capítulos de La utopía arcaica parecen ser Ideología mesiánica del mundo andino, Las paradojas del Perú oficial y sus tesis en Oxford sobre la "idea de historia" en Guamán Poma. No olvidemos además que su relación académica y personal se remonta a las épocas de la Comisión Ucchuraccay y la campaña política del Fredemo.
} 
indigenismo, la "religiosidad andina" supervive agazapada detrás de cada ritual y de cada templo católico.

Lo interesante es que fueron los propios narradores andinos (como Santa Cruz Pachacuti) quienes no sólo reconocieron antecedentes prehispánicos en muchos símbolos y rituales católicos, sino que incluso, anunciaron una evangelización temprana por obra de San Bartolomé el apóstol viajero. En el fondo de esa estrategia de enunciación, latía el deseo de homologar en el sistema colonial a los pueblos andinos, es decir un deseo elocuente de inclusión. Lamentablemente la ideologización del debate, ha impedido conclusiones de consenso.

Lo que si queda claro es que muchos intelectuales herederos del indigenismo (a menudo de universidades del interior del país) sospechan prescindiendo de los hechos, que si bien las comunidades rurales de la sierra pueden estar plenamente incorporadas a la economía de mercado desde mediados del siglo $\mathrm{XX}$, les seduce la idea de que "sus mentes y sus corazones" siguen siendo "andinos".

Esta formulación a-histórica se conjuga a menudo con una subvaloración del desarrollo capitalista en la sierra (la semi-feudalidad), destacando la "resistencia" de las formaciones sociales andinas a la expansión del mercado y concluyendo la más de las veces en proclamas de activismo político con grupos "nativistas", "indianistas y "nacionalistas".

Sin embargo, comparándolas con otros cielos, no parece tan novedoso. ${ }^{9}$ Si se los inserta en la categoría de campesinos muchas de sus características que se presumían como propias (el autoconsumo, la solidaridad, la cultura material) aparecen ahora como típicas del universo rural, aquí en Cangallo, en el Magreb o Punjab.

Así la naturaleza animada conforma el utillaje conceptual de "un mundo encantado" propio del precapitalismo. No olvidemos, que la reacción contra el racionalismo del siglo XVIII, fue hecha por teólogos alemanes, que se resistieron a considerar al hombre como libre de la religión, las ideas y las lenguas que las dotaban de significado. Este movimiento denominado romanticismo fundó una persuasiva visión del hombre y su cultura como originales, arquetípicos y singulares.

Lenin (s/f) entrevió por ejemplo que el culto al "alma rusa" que descansaba en las comunidades rurales y nubes de cosacos de las propuestas populistas, tenía severos límites (como "la crítica sentimental al capitalismo") desarmándola como un armatoste hecho por intelectuales que sentían horror de que el capitalismo arrollase las formas de vida aldeanas. ${ }^{10}$ Un horror urbano

\footnotetext{
${ }^{9}$ Eso explica en muchos casos la rigidez intelectual de muchos de sus intelectuales. Saben que las extensas comparaciones interculturales sólo confirmaría el "provincialismo" de sus propuestas.

10 "La idealización de la pequeña producción nos revela otro rasgo característico de la crítica romántica y populista: su carácter pequeñoburgués. Hemos visto como el romántico francés y
} 
ajeno al campesino y que Lukács llamaría después el "anticapitalismo romántico".

Este animismo y ensoñación de la realidad estuvo además, anclado en un lirismo exultante y en un lenguaje poético significativo. En Los ríos profundos es donde muestra con maestría esa cualidad de nombrar las cosas con bellas metáforas. Ya Miguel Gutiérrez (2008: 205) ha señalado que frente al lenguaje "chato" del realismo vargallosiano, emergen altivas, narrativas como las de Ciro Alegría, Arguedas o García Márquez.

"Yo había conocido el mundo todo a través del quechua, y cuando lo escribía en castellano me parecía éste idioma sumamente débil o extraño" (citado por Rowe 1979:45) había dicho Arguedas en el Primer Encuentro de Narradores Peruanos celebrado en Arequipa en 1965. El uso del idioma quechua y de su lógica le fue útil para expresar los sentimientos íntimos en sus cuentos y novelas. Quizás el nudo de sensibilidades que exuda el conjunto de su obra narrativa, sólo pudo haberse resuelto a través del lenguaje, es decir un castellano con la estructura quechua.

William Rowe afirma que Arguedas supera el indigenismo tradicional, por tres mecanismos básicos. Uno de ellos sería el uso del lenguaje. Al igual que Calendario Navarro, quien en Canto de Sirena (1976) el campesino negro se expresa con toda su humanidad y plena autoridad etnográfica; superando estilísticamente (e ideológicamente) al costumbrismo de Diez Canseco o Gálvez Ronceros ("desde entonces me entró fuerte la maña de golpear a cuanto blanco atrevido me saliera con vainas y con morisquetas"), en Arguedas el lenguaje sintetiza su mirada desde el interior del mundo indígena.

Y por último, el estudio recalca una cierta visión dual del mundo que narra: sierra/ /costa/ deseable/infame viril/femenina. Estos reflejos que pueden rastrearse desde Tempestad en los Andes han sido comunes en la producción indigenista y post-indigenista. Tiene que ver con la percepción del pasado pre/colonial como un paraíso perdido y de simplificar la estructura social en conflicto, para ofrecer mensajes didácticos a un lector ávido de exotismos y de reformas sociales.

Sin embargo la escritura de Arguedas es más compleja de lo que La utopia arcaica explica. Si nos atenemos a Moore en su libro sobre la novela Todas las sangres, el sociólogo Bourricaud habría expresado que el universo social se amplia en las novelas de Arguedas, superando el esquematismo y "enfrentando a personajes que pertenecen al mismo grupo sociocultural" (2003:72).

En conclusión La utopia arcaica fue criticada tajantemente por aquellos que se consideran los "herederos" de Arguedas y que desde su militancia en la izquierda que suele rondar el parlamento, creyeron que era más fácil anteponer una diferencia absoluta entre el nacionalista y el cosmopolita, entre el solidario 
con la revolución y el ultraliberal, entre el que sufría el país y el que lo citaba cómodamente (de la Cadena 1997, Mujica 1997, Montoya 1998, Pajuelo 1999).

Por ejemplo Mujica (43) llega a afirmar que las "sociedades duales" como la andina "siguen enmarcando el orden político, económico, social y religioso dentro de un orden metafísico" (las cursivas son nuestras) y mencionando para confirmar su afirmación, a antropólogos como Ossio, Salvador Palomino y Billie Jean Isbell, es decir el establishment andinista que ya fuese apelado por Orin Star. ${ }^{11}$

Aunque al término de su pequeño artículo (44) alega para respaldar su propuesta retro, de que la "filosofía postmoderna" ha opacado el "poder monopólico totalitarista" del racionalismo moderno que estaría personificado en Vargas Llosa. Solo mencionaremos que a más de una década de haberse publicado el artículo, ni la "filosofía postmoderna" resultó imponente ni el racionalismo (tal como lo entendió Mujica) fue derrotado.

Montoya (1998) en su artículo sobre La utopía arcaica incluido en un libro donde reúne textos vinculados a la multiculturalidad y los derechos indígenas, es también ilustrativo. Nos da la impresión de que el autor hubiese leído el libro al revés. No refuta el libro mencionado desde su literalidad, sino desde la circunstancias políticas que giraron (y giran) alrededor de los novelistas en pugna.

Más bien el artículo resalta al autor de Agua dentro de una composición muy cercana a la hagiografía: "Arguedas es en el Perú de hoy un héroe cultural, una figura mayor, un ejemplo a seguir" (205) "Seguramente hay millares de personas identificadas con Arguedas, convencidas de que su ideal Todas las sangres como unidad de la diversidad para el Perú del futuro es un sueño posible" (208).

Como un ejercicio paralelo podríamos afirmar también que la crítica a la novelística de James Baldwin sería más certera si la hiciera Malcom X que por ejemplo Harold Bloom, es decir el predominio de la militancia política o religiosa frente al estudio crítico.

Ramón Pajuelo también hace una cerrada defensa de la figura del novelista andahuaylino ante el texto de Vargas Llosa. Escribe que "la mirada del crítico (Vargas Llosa) es sumamente pobre, pues Arguedas fue mucho más allá" (177). Ese "más allá" es la hipótesis que sólo una corriente de antropólogos, militantes y activistas, cree descifrar. No es sólo proclamar la democracia o la multiculturalidad en un país como el nuestro, sino también de reconocer que el examen de esos términos son necesarios para construir lo que el articulista llama "una utopía para el futuro", términos problemáticos y que requieren ser re-pensados y esto no puede hacerse escamoteando algunos principios indelebles de la modernidad que tan alegremente se cuestionan.

11 "Tratar a la cultura como si fuera lo mismo que la sociedad es uno de los problemas más antiguos en las ciencias sociales. En antropología colonial, eso nos llevó directamente a la mentira tribal que identifica una cultura con una población encerrada en si misma: todo lo contrario de lo que podía desear un multiculturalista" Baumann: 144. 
Por ejemplo, si se revisa -los menciono al azar- las reflexiones de Favre sobre la democracia (2006) o las de Baumann (2001: 143) sobre la multiculturalidad (donde califica de mentira a la "etnopolítica"), se verá que la retórica laudatoria no puede remontar la "densidad" de la realidad social y que la homogeneidad de las afirmaciones reseñadas, pareciese que legitiman demandas represivas (por el abuso de adjetivos) para una conformidad cultural desde "lo andino".

La antropóloga de la Cadena (1997) es la que a mi juicio, intenta una crítica más sistemática y ordenada del libro de Vargas Llosa. Su principal hipótesis es que el novelista utiliza la figura de Arguedas para "entrar "científicamente" en la comunidad intelectual-política internacional y nacional" (el entrecomillado es de la autora), le replica que así como ella no puede criticar textualmente la obra de un literato si puede hacerlo en lo que se refiere a su campo de acción, en ese sentido, es que se aboca a desmontar brevemente los conceptos que sobre el indigenismo y el mestizaje desarrolla Vargas Llosa.

Sin embargo creo que el novelista no necesita acreditarse ante la comunidad académica. Las opiniones de un novelista son tomadas como tal y si, es cierto que un escritor posee más erudición y sus fronteras son más amplias que las de un académico positivo.

La antropóloga quien ha hecho un detallado estudio sobre la etnicidad en el Cusco de las primeras décadas del siglo XX, sabe que el indigenismo fue una práctica y un discurso de sectores mestizos y pequeños "blancos" que deseaban inventar una tradición con el cual enfrentar a la poderosa oligarquía limeña. Y esto no es nuevo, se remonta hasta Garcilaso y Guamán Poma que construyeron un asidero en el cual sujetarse ante el terremoto social que represento el orden colonial.

También significó que ante una estructura social tan confusa -hacendados aindiados, mestizos profesionales, blancos comerciantes y extranjeros avenidos- se tuvo que diseñar la "decencia" para zanjar las diferencias ahí donde los límites eran tan precarios.

Y obviamente, los intelectuales eran "decentes" y tanto, que en su altruismo defendieron al indio y narraron sus desgracias en sus novelas y en la activa prensa cusqueña.

Vargas Llosa pues no estuvo tan lejos en sus reflexiones sobre el pensamiento indigenista y cuando la articulista le reprocha su interés por disociar la literatura de la política, acercándolo a las posturas de Riva-Agüero o Víctor Andrés Belaúnde, no lo creo. Más bien estos representantes del pensamiento conservador y castrense si participaron activamente en política, tanto que ya David Sobrevilla (1976) ha explicado que en la tesis juvenil de Riva-Agüero sobre la literatura peruana ya están incubadas en sus líneas, sus futuras ideas políticas y sociales.

Si bien quizás no cita con pertinencia a los autores de moda -el vicio nacional de la mutua admiración- logra en sus obras una arquitectura sociológica 
bastante firme. Por ejemplo en La guerra del fin del mundo, a pesar de ser una re-escritura del libro de da Cunha y de incorporar meramente la ficción (las "mentiras" que irritan a Montoya) se notan las cualidades que autores como Lanternari adjudicaron para los movimientos mesiánicos.

Si nos atenemos al historiador italiano en su análisis "tipológicofenomenológico" de este tipo de movimientos, la novela sobre El Consejero reúne esas características: un profeta/ guía, un mito originario de la que el profeta encuentra la "revelación" o la "visión" y el postulado del "regreso a los orígenes" que es siempre una edad de oro. Es decir, a pesar de su plena ficción se palpa el "tipo ideal" del milenarismo tal como lo planteó Worlsley (1980), un exasperante hoy y el anhelo de una mañana feliz.

Igualmente uno queda impresionado cuando la investigadora Konig (455) menciona que en el archivo de los Mario Vargas Llosa Papers de la Universidad de Princenton "se encuentran cuatro archivadores con material etnográfico sobre los machiguengas". Es decir una novela si bien se construye de invenciones y originalidad, descansan también (pues se narra la vida humana) en miradas y documentación sociológica.

Finalmente es necesario reflexionar sobre la famosa Mesa Redonda y que en cierto modo se ha prestado para la mitificación. Estas reuniones realizadas en el Instituto de Estudios Peruanos, tenían por objetivo contrastar lo que expresaba la novela Todas las sangres, con la opinión de los científicos sociales. Si fueron reuniones malhadadas, quizás se debió a la época.

No es fácil hoy ofrecer una lectura de lo sucedido, 45 años después. Hoy las relaciones entre la literatura y las ciencias sociales son más fluidas que aquella fecha. La semiótica y el estructuralismo antropológico tienden efectivamente puentes y dotan de fertilidad la relación entre ambas esferas de conocimiento.

Sin embargo, muchos prejuicios sobre esas reuniones aún se mantienen. La estudiosa Moore (2003) en la última parte de su libro, intenta aun hoy, ser hipercrítica con las ciencias sociales, y lo más curioso aún, apunta escamoteando la participación de Quijano o Matos Mar- a fijarse en la participación de Henri Favre.

Sin embargo, las posturas de 1965, efectivamente estuvieron desde su inicio, planteadas singularmente. La cuestión parte de que el mismo Arguedas aceptaría la denominación de Todas las sangres como una novela social. Y como tal, las reuniones tuvieron como dinámica tratar de encontrar en el texto algunas claves de realismo etnográfico e histórico sobre el poder en los Andes. Hoy obviamente, no se plantearía de ese modo la cuestión. A pesar de que por ejemplo, algunos sociólogos como Julio Cotler en su libro "Clases, estado y nación en el Perú" incluye en su bibliografía novelas como El mundo es ancho y ajeno o Yawar Fiesta para ejemplificar la expansión latifundista en el primer tercio del siglo XX o los conflictos intercomunales en la sierra peruana.

Ya mas adelante Montoya dejaría trunco su proyecto de incluir algunos textos de Arguedas en su tesis doctoral sobre el eje productivo Puquio-Lomas-Acarí. 
En ese sentido, Moore critica la postura "hiperrealista" de Favre (aunque curiosamente Arguedas mismo abogaba de que su novela no era irreal, pues se había alimentado de la vida que él conocía) sin embargo esa acusación viene de las buenas intenciones de una profesora inglesa de literatura. Pero Favre no era un aficionado.

Había llegado con Francois Chevalier -el estudioso de los latifundios mexicanos- y a cargo de la Misión Etnológica Francesa había ayudado a diseñar un proyecto sobre la formación de haciendas, auspiciado por el flamante Instituto Francés de Estudios Andinos y el Departamento de Antropología de la Universidad de San Marcos (Fuenzalida 1965: 13-15).

Una región elegida en dicho proyecto, era la costa norte que indicaba un desarrollo "dinámico" del capitalismo agrario y del otro, una región reputada de "tradicional": Huancavelica. Favre se encargó de esta última durante el periodo 1964-65, y es bien conocido su estudio sobre las haciendas huancavelicanas. ${ }^{12}$

Si bien, no hizo el libro que prometió, en un libro posterior Cambio $y$ continuidad entre los Mayas de México de 1973, expone su hipótesis de que lo indio en Mesoamérica tenía ante todo que ver con mecanismos de explotación socio-económica y que una vez subvertidos estos, probablemente el concepto y contenido de lo indio, cambiaría.

Otro concepto interesante era que la "cultura andina" era en gran medida forjada en lo que llamó el "crisol colonial", anteponiéndose al razonamiento estático de la antropología de la época. Todas estas reflexiones las infirió de su trabajo en Huancavelica y sobre todo, de la zona de Moya (al norte del departamento y muy cerca del valle del Mantaro).

En un artículo (1983/84) en la que reflexiona sobre los efectos paradójicos que habían producido las leyes liberales sobre la sociedad andina, expuso tres fenómenos que cancelarían la "herencia colonial" ya entrado el siglo XVIII, ${ }^{13}$ cambios lentos pero inexorables, y que curiosamente los antropólogos ignoraban, en su afán de aferrarse a un mundo idílico andino.

Estos mecanismos eran la atomización política, es decir la ruptura de la articulación pan-andina de las reducciones indígenas alrededor de su condición de tributarios creando una férreo localismo, la disolución étnica, producto de la crisis de las élites nativas y el olvido de sus identidades culturales y su proclamación como aldeas rurales y por último, la homogenización social, en que la abigarrada diferenciación andina (nativos, forasteros, caciques, mitayos, temporeros, etcétera) se fue constituyendo lentamente en el campesinado de una nación.

\footnotetext{
12 "Evolución y situación de la hacienda tradicional de la región de Huancavelica" en Revista del Museo Nacional (33) 1967.

${ }^{13}$ En "Bolívar y los indios" Histórica (10) 1,1986:1-18, Favre vuelve a mostrar en la post independencia americana, la paradoja del rechazo indígena al ideario liberal en Pasto, la Gran Colombia. Las revueltas iquichanas de Navala Huachaca serían esa expresión en un escenario más cercano.
} 
Es por ello que en la Mesa redonda de 1965, Favre contraponía su experiencia sociológica con las comunidades huancavelicanas con la ficción afincada en los recuerdos que expresaba Todas las Sangres. Así se explica porque en los "universos narrativos" de Arguedas existe una aparente fisión en la geografía social de su obra. La sierra central y el valle del Mantaro ocupan sus estudios etnológicos y el entusiasmo por el mestizaje y la modernización; el sur andino la ficción retiene no sólo la poesía, el dolor y la nostalgia, sino también la esperanza.

Finalmente, si bien en Vargas Llosa la creación literaria es un "acto de rebeldía", en que la insatisfacción del autor con el mundo genera la necesidad de crear mundos alternativos o paralelos como el sexo, la locura o los paraísos sociales (un prostíbulo en medio del desierto piurano o el reino de los elegidos), donde la literatura se transforma en una verdad (que es una mentira) que satisface al inconforme.

En Arguedas la escritura fue una forma de blandir sus recuerdos y sus experiencias más dolorosas y que compaginadas con la realidad andina que como antropólogo conocía, nos mostró un Perú lacerado. El discurso de recepción del Nóbel de Literatura 2010 en que el afamado novelista menciona su admiración por José María Arguedas salda definitivamente esa aparente escisión.

Lima, verano del 2011

\section{Bibliografia}

Aínza Fernando (1992) "De la edad de oro a El Dorado: génesis del discurso utópico americano" México, Fondo de Cultura Económica.

Álvarez Lobo, Ricardo prólogo. (2006) "La vida del pueblo Matsigenga: aporte etnográfico de los misioneros dominicos al conocimiento de la cultura matsigenga (1923-1978)" Lima, Centro Cultural Pío Aza.

Angvik, Birger (2004) "La narración como exorcismo. Mario Vargas Llosa, obras (1963-2003)" Lima, Fondo de Cultura Económica.

Arguedas José María

s/f "La agonía de Rasu-Ñiti" Lima, Populibros.

1972 "Los ríos profundos" Lima, Retablo de Papel.

Baumann Gerd (1999) "El Enigma Multicultural: un replanteamiento de las identidades étnicas, religiosas y nacionales" Barcelona, Paidós.

Bellini Giuseppe (1992) "Función del símbolo en Los ríos profundos de J. M. Arguedas" en Anthropos (128) enero: 53-56. 
Cadena de la, Marisol (1997) "Mario Vargas Llosa y el "mundo andino". A propósito de La Utopía arcaica y las ficciones del indigenismo" en Ideele (100) agosto-setiembre: 63-68.

Favre Henri

1967 "Evolución y situación de la hacienda tradicional de Huancavelica" en Revista del Museo Nacional (33): 237-257

1983/85 "El mundo andino en tiempos de Bolívar: los Asto entre 1780 y 1830" en Revista del Museo Nacional (47): 260-271

1986 "Bolívar y los indios" en Histórica (10) 1: 1-18.

2006 "La democracia y sus fundamentalistas" en Cuadernos Americanos (115): 111- 117.

Forgues Roland (1993) "José María Arguedas: la letra inmortal correspondencia con Manuel Moreno Jimeno" Lima, s/e.

Fuenzalida Fernando (1965) "Investigaciones etnológicas en el departamento de Huancavelica 1964-1965" en Cuadernos de Antropología (3) 8, diciembre: 13-15.

Gutiérrez Miguel (2008) "La generación del 50: un mundo dividido" Lima, Arteidea.

Henighan Stephen (2009) "Nuevas visiones de lo femenino en La Fiesta del Chivo, El Paraíso en la otra esquina y Travesuras de la niña mala" en Hispanic Review (77) 3: 369-388.

Instituto de Estudios Peruanos (1985) "?He vivido en vano? Mesa redonda sobre Todas las sangres" Lima, IEP.

Jameson Fredric (1998) "Teoría de la postmodernidad" Madrid, Trotta.

Konig Brigitte (2001) "Metalinguística y oralidad fingida en Mario Vargas Llosa" en Mario Vargas Llosa. Escritor, ensayista, ciudadano y político, Roland Forgues editor. Lima, Minerva.

Lanternari Vittorio (1965) "Movimientos religiosos de libertad y salvación de los pueblos oprimidos" Barcelona, Seix Barral.

Lenin V.I. s/f "Carácter de la crítica del capitalismo en los románticos" en Sobre el problema de los mercados. Escritos económicos (1893-1899) Lima, Ediciones Populares.

Meneses Porfirio (1974) "Cholerías 2" Lima, Los Andes.

Meseth de Bona, Gabriel (2009) "Paraísos perdidos. Nociones de utopía según los personajes históricos de El paraíso en la otra esquina, de Mario Vargas Llosa" Lima, Tesis de Licenciatura en Literatura Hispánica, PUCP. 
Montoya Rodrigo (1998) "Todas las sangres: ideal para el futuro del Perú. Crítica del libro La utopía arcaica" en Multiculturalidad y Política: derechos indígenas, ciudadanos y humanos. Lima, Sur.

Moore Melisa (2003) "En la encrucijada: las Ciencias Sociales y la novela en el Perú. Lecturas paralelas de Todas las Sangres" Lima, Fondo Editorial UNMSM.

Mujica Pinilla Ramón (1997) "Mario Vargas Llosa y la negación occidental del mundo andino" en Debate (19) 94, mayo-junio: 40-44.

Pajuelo Ramón (1999) "La crítica arcaica. Mario Vargas Llosa y las ficciones de la razón modernizante" en Runamanta (1) diciembre: 173-178.

Rowe William (1979) "Mito e ideología en la obra de José María Arguedas" Lima, INC.

RUNA (1977) revista del Instituto Nacional de Cultura (6) noviembre-diciembre, Homenaje a José María Arguedas.

Shlickers Sabine (1998) "Conversación en la catedral y La Guerra del Fin del Mundo de Mario Vargas Llosa: novela totalizadora y novela total" en Revista de Crítica Literaria Latinoamericana (48) 2do. Semestre: 185-211.

Snell Wayne (1977) "El sistema de parentesco entre los machigengas" en Historia y Cultura (6): 277-292.

Sobrevilla David (1976) "La critica de la literatura peruana" en Proceso (5): 1520.

Starn Orin (1992) "Antropología,"andinismo" y Sendero Luminoso" en Allpanchis (39): 15-71.

Todorov Tzvetan (2003) "Nosotros y los otros" Madrid, Siglo XXI.

Valcárcel Luis E. (1981) "Memorias" Lima, Instituto de Estudios Peruanos.

Vargas Llosa Mario

1977 "José María Arguedas entre sapos y halcones" en Boletín de la Academia Peruana de la Lengua (12): 89-117.

1981 "La Guerra del Fin del Mundo" Barcelona, Seix Barral

1987 "El hablador" Barcelona, Seix Barral.

1996 "La utopía arcaica. José María Arguedas y las ficciones del indigenismo" México, Fondo de Cultura Económica.

2003 "El Paraíso en la otra esquina" Lima, Alfaguara.

Worsley Peter (1980) "Al son de la trompeta final. Un estudio de los cultos "cargo" en Melanesia" Madrid, Siglo XXI. 